\title{
Toward reliable morphology assessment of thermosets via physical etching: Vinyl ester resin as an example
}

\author{
S. Grishchuk ${ }^{1}$, A. Bonyár ${ }^{2}, J$. Elsäßer ${ }^{3}$, A. Wolynski ${ }^{4}, J$. Karger-Kocsis ${ }^{5,6^{*}}$, B. Wetzel ${ }^{1}$ \\ ${ }^{1}$ Institut für Verbundwerkstoffe GmbH (Institute for Composite Materials), University of Kaiserslautern, \\ Erwin-Schrödinger Str. 58, D-67663 Kaiserslautern, Germany \\ ${ }^{2}$ Department of Electronics Technology, Budapest University of Technology and Economics, H-1111 Budapest, Hungary \\ ${ }^{3}$ Arbeitsgruppe Werkstoff- und Oberflächentechnik Kaiserslautern (Workgroup Materials and Surface Technologies), \\ University of Kaiserslautern, Erwin-Schrödinger Str. 58, D-67663 Kaiserslautern, Germany \\ ${ }^{4}$ Photonik-Zentrum Kaiserslautern e.V., Kohlenhofstr. 10, D-67663 Kaiserslautern, Germany \\ ${ }^{5}$ MTA-BME Research Group for Composite Science and Technology, Müegyetem rkp. 3, H-1111 Budapest, Hungary \\ ${ }^{6}$ Department of Polymer Engineering, Faculty of Mechanical Engineering, Budapest University of Technology and \\ Economics, H-1111 Budapest, Hungary
}

Received 30 November 2012; accepted in revised form 13 January 2013

\begin{abstract}
The morphology of peroxide-cured, styrene crosslinked, bisphenol A-based vinyl ester (VE) resin was investigated by atomic force microscopy (AFM) after 'physical' etching with different methods. Etching was achieved by laser ablation, atmospheric plasma treatment and argon ion bombardment. Parameters of the etching were varied to get AFM scans of high topography resolution. VE exhibited a nanoscaled nodular structure the formation of which was ascribed to complex intra- and intermolecular reactions during crosslinking. The microstructure resolved after all the above physical etching techniques was similar provided that optimized etching and suitable AFM scanning conditions were selected. Nevertheless, with respect to the 'morphology visualization' these methods follow the power ranking: argon bombardment > plasma treatment $>$ laser ablation.
\end{abstract}

Keywords: thermosetting resins, physical etching, morphology, nodular structure, structural inhomogeneity

\section{Introduction}

There is a long lasting dispute on whether the structure of thermosets becomes homogenous or heterogeneous after their curing. Usual arguments for homogeneity list the appearance of a sharp, well detectable glass transition relaxation, no direct evidence of heterogeneity by electron microscopy techniques, perfect agreement with conversion calculations accepting a single curing mechanism. For amine-cured epoxy (EP) systems for example it has been quoted that their structure is homogenous and results against this claim are linked with artifacts, especially when resolved in nanoscale ([1] and references therein).

Atomic force microscopy (AFM) seems to be one of the best tools to study the morphology of cured thermosets. Using its phase contrasting tapping mode one can resolve the eventually present twophase structure provided that the corresponding phases have a large enough difference in their stiffness and related characteristics (e.g. hardness). Supposing ab ovo that the network structure of thermosets is inhomogeneous, the degradation of its constituents should be different, as well. This fea-

\footnotetext{
${ }^{*}$ Corresponding author, e-mail: karger@pt.bme.hu

(C) BME-PT
} 
ture can be exploited for the 'visualization' of the morphology via controlled degradation of the phase constituents. For that purpose various physical etching techniques may be used. However, to explore their applicability, it is straightforward to use suitable model materials, such as vinyl ester (VE) and resin blends [2]. Commercial VEs may contain up to $50 \mathrm{wt} \%$ styrene comonomer and their curing is induced by peroxides in presence or absence of accelerators. Considering the fact that VE is tetrafunctional (bearing two double bonds), whereas styrene is bifunctional, the 'real' crosslinking agent is the VE itself in VE/styrene formulations. During curing of VEs different coreactions may occur. Beside of the favored VE/styrene copolymerization, VE/VE and styrene/styrene homopolymerizations may take place. There is a difference in the reactivity ratios of the above listed possible reactions. In addition, the growing, branching chains may be involved in intra- and intermolecular reactions. Last but not least the gelling phase, occurring during crosslinking, strongly affects the course of the various reactions through hampering the molecular diffusion. The above scenario already suggests that VE and similar systems should possess a heterogeneous structure. This has been proved on unetched samples by AFM [1,3-4] and even by scanning electron microscopy [5]. By the latter method micronscaled, whereas with the AFM nanoscaled domains, called nodules, were detected. The corresponding structure is frequently termed as microgel. The AFM scans were sometimes of low quality and thus less suited for an insight in the morphology [3]. Detectability of the morphology was prominently improved by physical etching. VE samples were etched by laser treatment [6] and argon ion $\left(\mathrm{Ar}^{+}\right)$bombardment [7]. On the other hand, the nodules' size in the published works often differed from one another markedly. This may be due to differences in the type and composition in the VE resins (e.g. styrene amount, accelerator content) and due to artifacts generated by the physical etching techniques themselves. Nonetheless, it commonly accepted that the nodules formed by intramolecular reactions and they are VE-rich by contrast to the embedding matrix phase that is polystyrene-rich $[4,7]$.

The aim of this study was to get a deeper understanding in the morphology of VE by using various physical etching techniques whereby varying their conditions, and to check whether optimized etching parameters reveal the same morphology without artifacts. For VE etching laser ablation, atmospheric plasma treatment and $\mathrm{Ar}^{+}$bombardment were used. Note that in depth studies on the VE morphology are essential to reveal changes caused by recent modification strategies, such as resin hybridization [8] and nanofilling [9], as well.

\section{Experimental}

\subsection{Materials, sample preparation}

A styrene diluted bisphenol-A type vinyl ester (VE) Daron-XP-45-A2 from DSM Composite Resins AG (Schaffhausen, Switzerland) with a density of $1.080 \mathrm{~g} / \mathrm{ml}$, viscosity of $175-225 \mathrm{mPa} \cdot \mathrm{s}$ and styrene content of ca. $30 \mathrm{wt} \%$ was chosen for this study. Dibenzoyl peroxide (BPO; Perkadox CH50L: peroxide content $50 \mathrm{wt} \%$ ) and $\mathrm{N}, \mathrm{N}$-diethyl aniline (DEA; Accelerator NL-64-100) were purchased from Akzo Nobel (Düren, Germany) and used as initiator and accelerator for the free radical polymerization, respectively. The preparation procedure was as follows. First, 1.5 part per hundred resin [phr] of $\mathrm{BPO}$ was dissolved in the VE resin at ambient temperature at 800 revolutions per minute [rpm] mixing speed and the obtained mixture was degassed in vacuo. Then, $0.15 \mathrm{phr}$ of DEA accelerator was introduced. The mixture was mixed for additional $3 \mathrm{~min}$ at $800 \mathrm{rpm}$, degassed and introduced in open polytetrafluoro ethylene moulds. Plates $100 \times 8 \times 4 \mathrm{~mm}^{3}$ (length $\times$ width $\times$ thickness) were produced using the following curing regime: room temperature for $45 \mathrm{~min}, 50^{\circ} \mathrm{C}$ for $15 \mathrm{~min}, 80^{\circ} \mathrm{C}$ for $30 \mathrm{~min}, 140^{\circ} \mathrm{C}$ for $30 \mathrm{~min}$, and finally $180^{\circ} \mathrm{C}$ for 1 hour. The moulds were then cooled to ambient temperature overnight and the specimens removed, cut to the size $8 \times 8 \times$ $4 \mathrm{~mm}^{3}$ (length $\times$ width $\times$ thickness), fixed in cylindrical steel clips for mounting (Buehler GmbH, Düsseldorf, Germany), embedded in EpoFix bisphenol-A based $\left(M_{\mathrm{n}} \leq 700 \mathrm{~g} / \mathrm{mol}\right)$ triethylene tetramine curable mounting epoxy resin from Struers (Ballerup, Denmark). The embedding resin was cured overnight at ambient temperature in the pressure chamber Technomat from Heraeus Kulzer GmbH (Wehrheim/Ts., Germany) at 2 bar air pressure in order to remove the on the sample surface adsorbed air bubbles and ensure the good quality of embedding. Afterwards, embedded samples were polished at $300 \mathrm{rpm}$ using 
Buehler Alpha 2 speed grinder-polisher from Buehler $\mathrm{GmbH}$ (Düsseldorf, Germany) with silicon carbide grinding paper Buehler-Met ${ }^{\mathbb{B}} \mathrm{II}$ of different grits (from 800 to 4000) under continuous water flow cooling. Further polishing was performed using TegraPol-21 polishing machine with Tegra Force-5 head from Struers using diamond suspensions of $3 \mu \mathrm{m}$ and finally of $1 \mu \mathrm{m}$ corn size from Buehler (Lake Bluff, IL, USA). After final polishing procedure the samples were washed thoroughly with water and then in isopropanol in a Bandelin Sonorex Super RK 103 H ultrasound bath (Badelin Electronic, Berlin, Germany) working at $100 \%$ power $(320 \mathrm{~W})$ at a frequency of $35 \mathrm{kHz}$ for $2 \times 15 \mathrm{~min}$. The polished sides of the embedded specimens were cut to $1 \mathrm{~mm}$ thick plates using precise in-hole microsaw Leica 1600 from Leica Instruments $\mathrm{GmbH}$ (Nussloch, Germany) with diamond coated cutting unit Winter D46 JS 35D (Saint-Gobain Diamantwerkzeuge, Norderstedt, Germany), resulting in the $8 \times 8 \times 1 \mathrm{~mm}^{3}$ (length $\times$ width $\times$ thickness) embedded samples. The polished surfaces were rinsed with isopropanol once again prior to the physical etching.

\subsection{Physical etching}

For physical etching the following techniques were used: laser ablation (LA), plasma treatment (PT) and $\mathrm{Ar}^{+}$bombardment (AB).

The ultrafast laser system used for LA in this paper was a commercially available picoseconds [ps] laser system with $10 \mathrm{ps}$ pulse duration (HYPER25, Lumera Laser, Kaiserslautern, Germany). The experiments were run at a laser wavelength in the UV spectral range $(\lambda=355 \mathrm{~nm})$ and at high pulse repetition frequencies $(\mathrm{PRF}=200 \mathrm{kHz}$ ). For fast beam deflection a galvanometer scanner (hurrySCAN, Scanlab, Munich, Germany) was used at feed rates as high as $1400 \mathrm{~mm} / \mathrm{s}$. Using an $f=100 \mathrm{~mm}$ objective mounted at the scanner system's beam exit the laser beam was focused on the sample surface to a spot size of about $12 \mu \mathrm{m}$. The pulse energy was varied between 1 and $15 \mu \mathrm{J}$ during the laser treatment of $5 \mathrm{~mm}$ long and $1 \mathrm{~mm}$ wide areas. In order to achieve the necessary topology an optimized pulse to pulse overlap was chosen, while the laser etching process was repeated up to three times per area. Accordingly, a sample designated as e.g. $3 \times 7 \mu \mathrm{J}$ means that the pulse energy was set to $7 \mu \mathrm{J}$ and the laser etch- ing process was repeated three times on the whole surface of the corresponding area.

Information on the topology was received by a chromatically encoded confocal measurement (CHRocodile E, Precitec Optronic GmbH, Ridgau, Germany) with an axial resolution of $35 \mathrm{~nm}$, (measuring rate $4 \mathrm{kHz}$, lateral measuring distance $\Delta x=$ $\Delta y=2.5 \mu \mathrm{m}$, feed rate $1 \mathrm{~mm} / \mathrm{min}$ ) yielding an arithmetic surface roughness $\left(R_{\mathrm{a}}\right)$ in the range of 260$480 \mathrm{~nm}$. It is noteworthy that in the pioneering work of Mortaigne [6] on the laser ablation of VE using a pulsed ArF excimer laser $(\lambda=193 \mathrm{~nm}, \mathrm{PRF} 10 \mathrm{~Hz}$, number of pulses 200, pulse duration $=16 \mathrm{ns)} \mathrm{an}$ ablation threshold of about $25 \mathrm{~mJ} / \mathrm{cm}^{2}$ laser fluence was determined. In our case LA etching process using $10 \mathrm{ps}$ laser pulses was observed at pulse energies as small as $1 \mu \mathrm{J}$, which corresponds to a laser fluence of about $1.7 \mathrm{~J} / \mathrm{cm}^{2}$. Note that the ablation threshold of 10 ps pulses was not determined in this work. The laser fluence (energy density, $E D$ ) was calculated from the pulse energy $\left(E_{\mathrm{p}}\right)$ and spot size (radius of the beam, $R$; here $6 \mu \mathrm{m}$ ) as follows taking into account the Gaussian character of the beam (factor 2 in Equation (1)):

$E D=\frac{E_{\mathrm{p}}}{\pi R^{2}}$

$E D$ is in the range of ca. $5.3 \mathrm{~J} / \mathrm{cm}^{2}$ and ca. $37.2 \mathrm{~J} / \mathrm{cm}^{2}$ based on the minimum $(3 \times 1 \mu \mathrm{J}=3 \mu \mathrm{J})$ and maximum $(3 \times 7 \mu \mathrm{J}=21 \mu \mathrm{J})$ conditions of the LA etching, respectively.

The basic event by using ultrashort laser pulses is the ablation of thin material layers in the order of tens of nanometers. This offers a reliable and high resolution etching process. In comparison to excimer lasers the PRF is several orders of magnitude higher, which will be advantageous for laser treatment of large areas.

Atmospheric low-frequency PT was performed in a Plasmatreater 400 (Plasmatreat GmbH, Steinhagen, Germany) in air. The related plasma jet system consists of one PTW10 nozzle mounted in parallel manner. This allows the treatment in $2 \mathrm{~mm}$ width. The following parameters such as plasma voltage $(280 \mathrm{~V})$, plasma current $(3.4 \mathrm{~A})$, plasma power $(21 \mathrm{kHz})$, plasma cycle time $(100 \%)$, initial pressure (1000 mbar) were kept constant. Variables of the PT were the distance of the substrate to the jet orifice $(5-20 \mathrm{~mm})$ and the nozzle feed velocity (5- 
$20 \mathrm{~m} / \mathrm{min}$ ). Each sample has got one single treatment. Unfortunately, here the authors were not able to estimate the surface-related PT energy.

In case of argon ion bombardment $(\mathrm{AB})$ the polished surface of the specimens was eroded by $\mathrm{Ar}^{+}-$ ions using a secondary neutral mass spectrometer (INA-X, SPECS GmbH, Berlin, Germany) operating at $500 \mathrm{eV}$ and at a plasma potential of ca. 40 $50 \mathrm{eV}$ using diaphragm of $10 \mathrm{~mm}$ in diameter. The incoming beam was oriented perpendicularly to the surface of the specimen. The distance $4.7 \mathrm{~mm}$ from the beam source to the surface of the specimen was set. The irradiation time, was the only parameter that was varied in three steps: 5, 10 and $20 \mathrm{~min}$. This resulted in overall ion doses of approximately $0.9 \cdot 10^{18}, 1.9 \cdot 10^{18}$ and $3.8 \cdot 10^{18} \mathrm{Ar}^{+} / \mathrm{cm}^{2}$, respectively. The corresponding surface related energy values are: $4.5 \cdot 10^{20}, 9.5 \cdot 10^{20}$ and $1.9 \cdot 10^{21} \mathrm{eV} \cdot \mathrm{Ar}^{+} / \mathrm{cm}^{2}$, respectively, calculated by multiplying the overall ion doses with their energy of $500 \mathrm{eV}\left(=8.01^{-17} \mathrm{~J}\right)$. The above data in the range of $72.1-304.4 \mathrm{~J} / \mathrm{cm}^{2}$ are estimated values. Note that $\mathrm{AB}$ etching with the middle flux value was already practiced for VE [7] and VE/EP hybrids [2].

\subsection{AFM testing}

For the AFM scans two devices were used, viz. MultiMode AFM-2 type NanoScope ${ }^{\circledR}$ IIIa from VeecoDigital Instruments (Mannheim, Germany) and diInnova type instrument of Bruker AXS (Karlsruhe, Germany). They are denoted next as AFM-a and AFM-b, respectively.

Scans with AFM-a were registered in tapping mode, and the related height-, amplitude- and phase-contrast images captured. An Al-coated (reflection side) N-type silicon (Si) cantilever $(125 \mu \mathrm{m}$ cantilever length, $4.5 \mu \mathrm{m}$ thickness, $35 \mu \mathrm{m}$ width), product of AppNano (Santa Clara, Ca, USA), with a nominal tip radius of less than $10 \mathrm{~nm}$, tip heigth of 14 $16 \mu \mathrm{m}$ and spring constant in the range of $25-$ $75 \mathrm{Nm}^{-1}$ (about $50 \mathrm{Nm}^{-1}$ ) was employed in the range of its fundamental resonance frequency of 200$400 \mathrm{kHz}$ (about $330 \mathrm{kHz}$ ). The scan rates were set at $0.5 \mathrm{~Hz}$ for all images.

The experimental conditions of AFM-b were as follow: tapping mode images were made with a Bruker RTESPA-CP type antimony (n) doped Si tip with a nominal tip radius below $10 \mathrm{~nm}(125 \mu \mathrm{m}$ cantilever length, $4 \mu \mathrm{m}$ thickness, $35 \mu \mathrm{m}$ width, $40 \mathrm{Nm}^{-1}$ spring constant and $300 \mathrm{kHz}$ resonance frequency). Amplitude, height and phase-contrast images were captured with a scan rate of $1 \mathrm{~Hz}$ and $512 \times 512$ sampling rate. During the scans the PID values of the scanner feedback were optimized according to the User Manual to gain the best image quality. For data evaluation the Gwyddion 2.27 software was used.

\section{Results and discussion}

\subsection{Laser treatment (LA)}

As expected based on the work of Mortaigne [6] there should be a lower ablation threshold that should be surpassed during etching. Figure 1 shows a series of AFM height, amplitude and phase contrast images taken from the VE etched by different LA parameters. One can notice that three times 5 to $7 \mu \mathrm{J}$ treatments gave an optimum topography. By contrast, etching two times by $10 \mu \mathrm{J}$ (that is comparable from the point of view of the overall dose) results already in a smeared surface due to obvious melting phenomena. This means that also an upper threshold exists for LA above which the bulk properties may prominently alter. Moreover, the latter threshold cannot be assigned to an overall dose because the dose in one step is of great relevance, too.

Albeit the microgel structure is well recognizable in most of the AFM-a scan in Figure 1, there is a large difference in their size compared to former results $[4,7]$ reporting on nanoscaled nodules. Based on Figure 2 the nodule size may reach $0.5 \mu \mathrm{m}$. However, the height scan from the same sample provided by AFM-b with a fresh cantilever revealed that the nodules are in nanoscale, in fact (cf. Figure 3). It is noteworthy that the 'used' cantilever in AFM-b yielded a similar morphology as AFM-a, as shown in Figure 2. Accordingly, the conditions of AFM testing should be properly set, and even the tip of the cantilever purposefully checked, in order to achieve the necessary resolution.

\subsection{Plasma treatment (PT)}

First the combined effects of the distance to nozzle/nozzle speed were checked in the range $5 / 5,7 / 7$, $10 / 10,15 / 15$ and $20 / 20[\mathrm{~mm} /(\mathrm{m} / \mathrm{min})]$ settings. Change in the surface relief was observed only at 10 


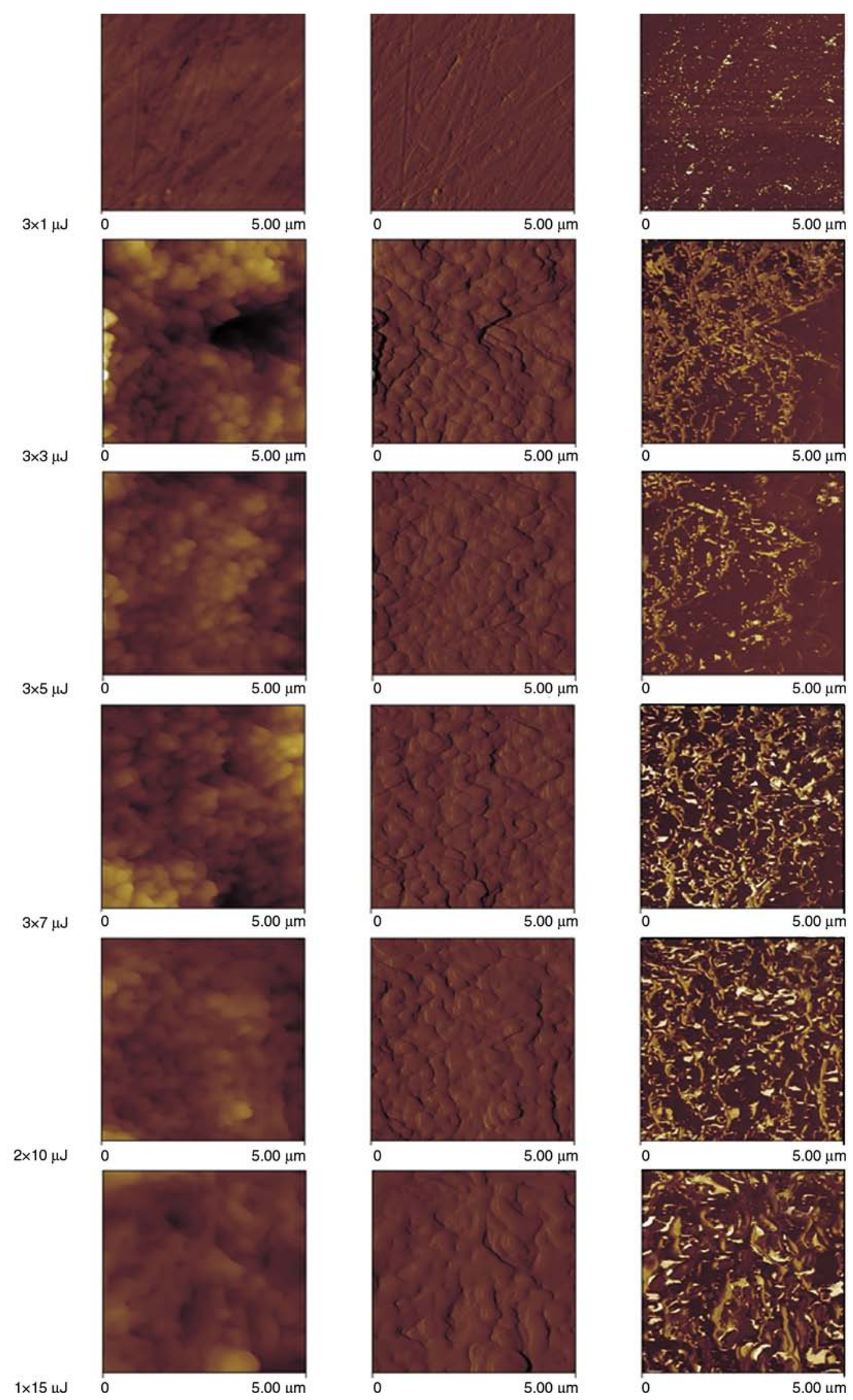

Figure 1. Height (left), amplitude (middle) and phase contrast (right) AFM-a scans taken from VE after different LA conditions 

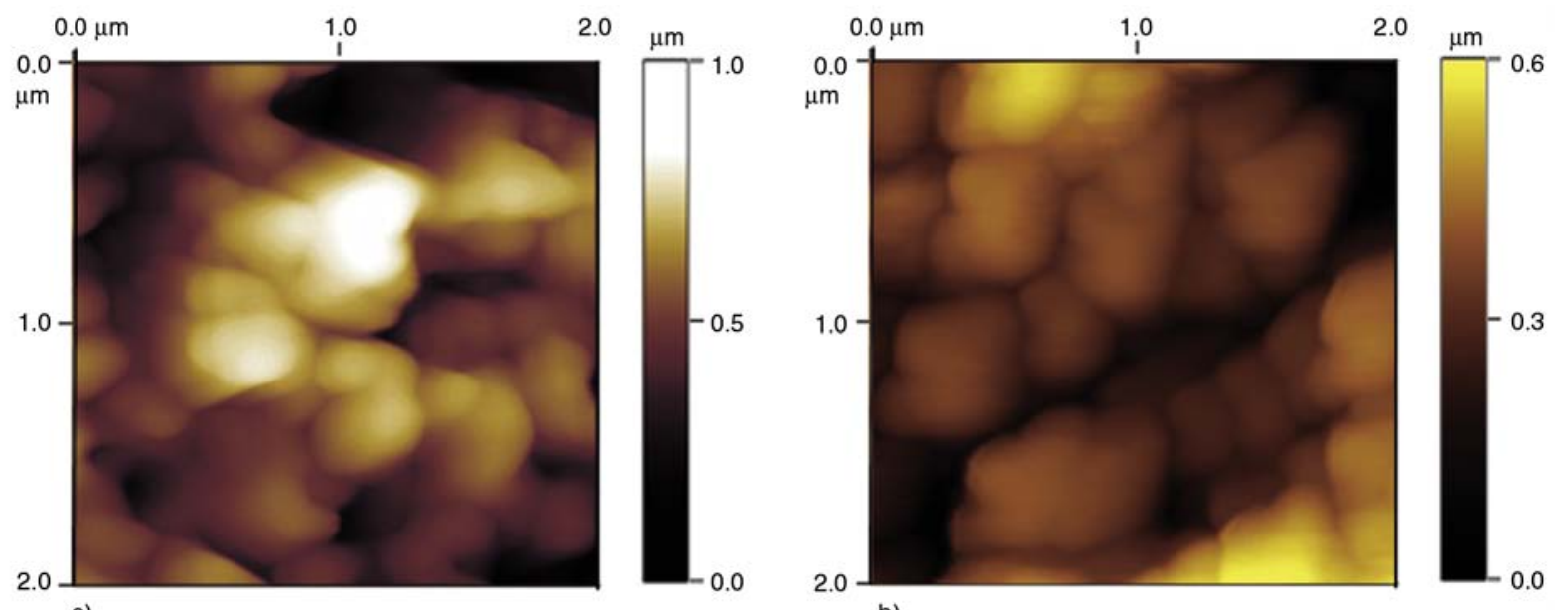

a)

b)

Figure 2. AFM-a (a) and AFM-b (b) height scans from VE etched by $3 \times 7 \mu \mathrm{J}$

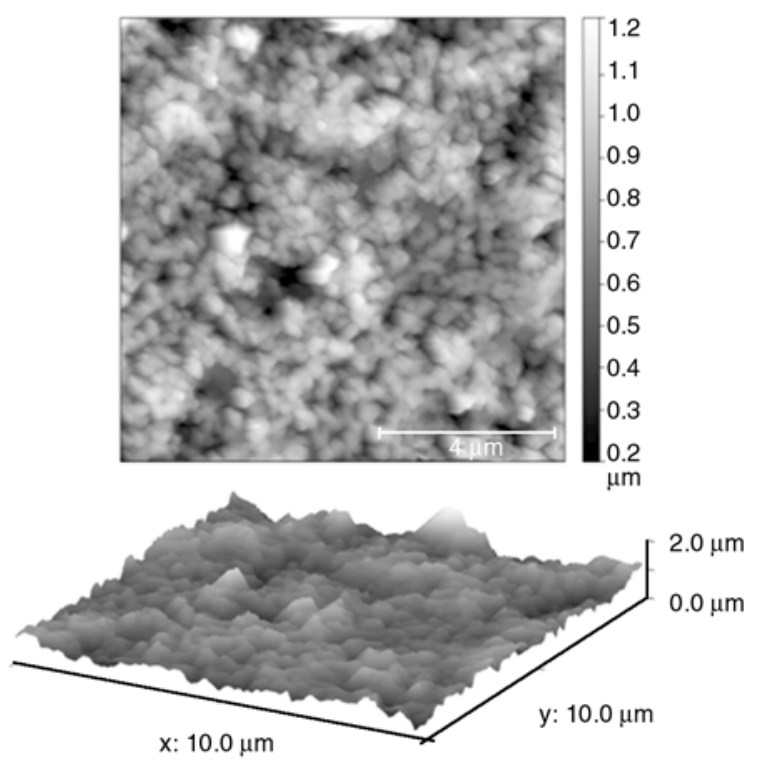

Figure 3. Two- and three-dimensional AFM-b scans from $\mathrm{VE}$ etched by $3 \times 7 \mu \mathrm{J}$ showing the existence of nanoscaled nodules

to $15 \mathrm{~mm}$ distances to nozzle and 10 to $15 \mathrm{~m} / \mathrm{min}$ speeds. Outside this range less surface roughening appeared according to the AFM-a scans in Figure 4. AFM scans registered on the VE after optimum PT conditions are given in Figure 5. The phase contrast picture in Figure 5 suggests, however, that even under these PT conditions surface melting took place and thus further 'tuning' of this etching technique is required.

The most important finding is, however, that the nodules' size range $(30-70 \mathrm{~nm})$ agrees reasonably with that of derived from Figure 3.

\subsection{Argon ion bombardment (AB)}

Figure 6 compares the AFM scans taken after AB with various $\mathrm{Ar}^{+}$ion fluxes. One can see that only highest flux yielded the expected surface morphology. This means that the use of $\mathrm{AB}$ also requires the determination of a threshold and most likely also a proper 'working' range for this kind of etching, as well.

Results in Figure 6d confirm that the size of the nodules is nanoscaled. They are in the range of 30 $100 \mathrm{~nm}$. This value is well matched with those derived after LA and PT performed in optimum etching conditions. Further, this nodules' range agrees fairly with that one found in our earlier work [7].

This means that all above etching methods may be used to visualize the morphology of thermosets after detecting the best etching conditions. As far as the methods concern, one can state that $\mathrm{AB}$ is more straightforward than PT or LA. This is the right place to underline that further considerable efforts are needed to find the right ways to reveal the morphology of thermosets. The physically etched surfaces should be subjected to analytical investigations covering Fourier transform infrared (FTIR), Raman and X-ray photoelectron spectroscopy analyses to clarify eventual chemical changes. Further, the etching in different atmospheres, combined with in depth analytics on the degradation pathways are further challenging and necessary tasks in this respect. 
a)
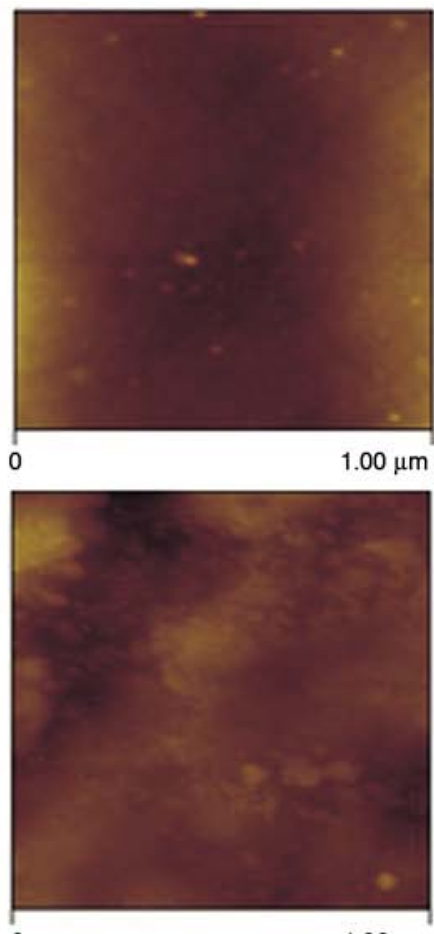
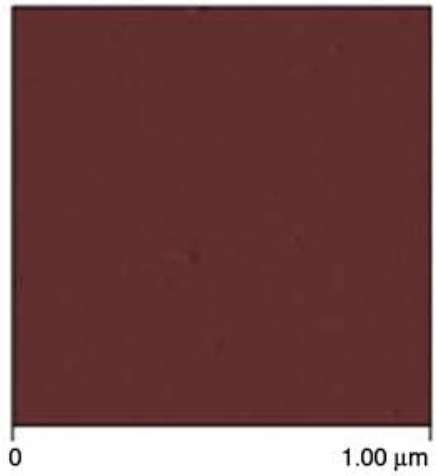

$1.00 \mu \mathrm{m}$

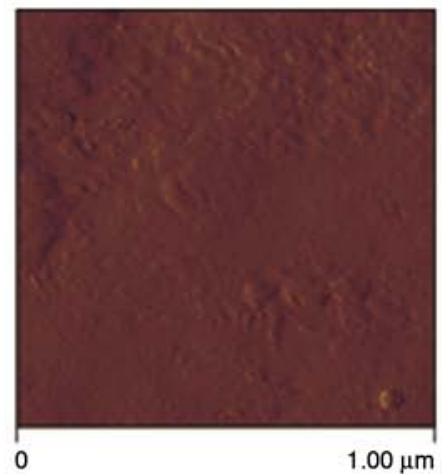

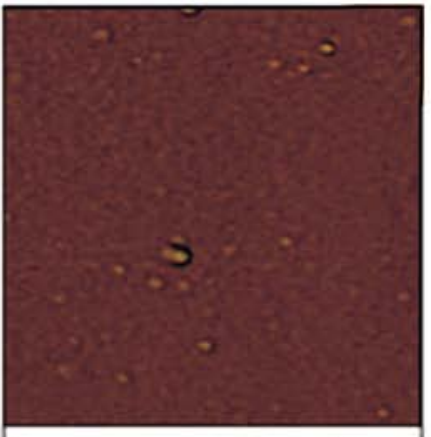

$1.00 \mu \mathrm{m}$

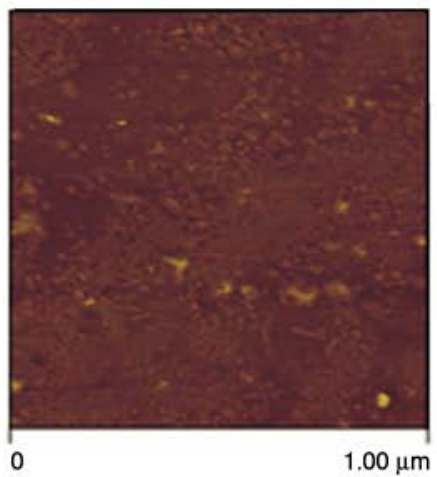

Figure 4. Height (left), amplitude (middle) and phase contrast images (right) taken by AFM-a after PT performed at distance/speed ratios of $7 \mathrm{~mm} / 7 \mathrm{~m} / \mathrm{min}$ (a), and $20 \mathrm{~mm} / 20 \mathrm{~m} / \mathrm{min}$ (b), respectively

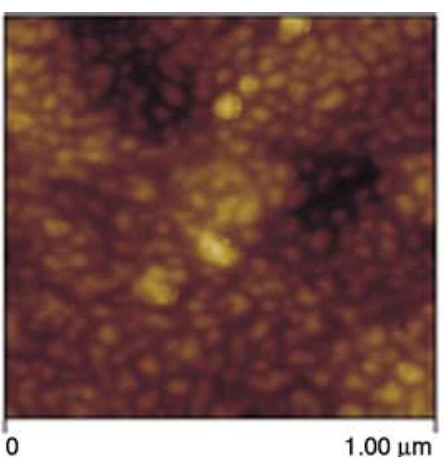

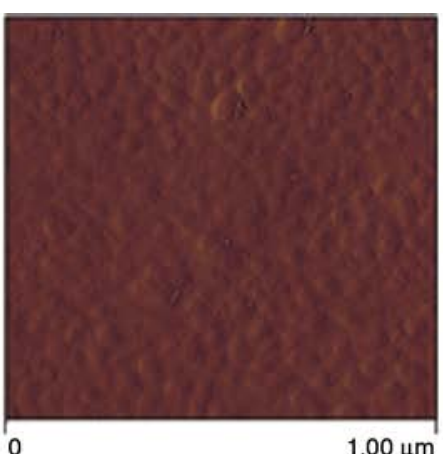

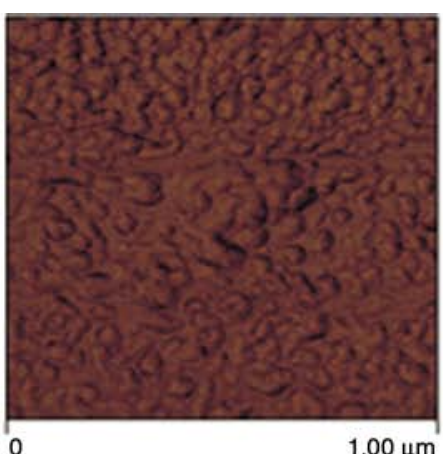

$1.00 \mu \mathrm{m}$

Figure 5. Height (left), amplitude (middle) and phase contrast images (right) taken by AFM-a after optimum PT conditions, viz. distance between substrate and nozzle $15 \mathrm{~mm}$ and nozzle speed $15 \mathrm{~m} / \mathrm{min}$

\section{Conclusions}

This work was devoted to the morphology detection of a cured vinyl ester (VE) resin by atomic force microscopy (AFM) after various 'physical' etching techniques, namely laser ablation (LA), atmospheric plasma treatment (PT) and argon ion bombardment (AB). It was established that all above techniques may be used when their conditions are adjusted to the related thermoset. In order to avoid etching technique-related artifacts, attention should be taken to define the 'working window', i.e. the range between lowest and highest etching/ablation thresholds, which reflect the initial structure adequately.

\section{Acknowledgements}

The research leading to the reported results has received funding from a German (DAAD) -Hungarian (MÖB) collaboration project and from the Hungarian Scientific Research Fund (OTKA-NK 83421). It was also connected to the scientific program of the 'Development of qualityoriented and harmonized $\mathrm{R}+\mathrm{D}+\mathrm{I}$ strategy and functional model at BME', supported by the New Hungary Development Plan (Project ID: TÁMOP-4.2.1/B-09/1/KMR-20100002). The authors are thankful to the following colleagues due their help in this work: M. Fejős (Budapest), Prof. P. Geiß, Prof. J. L'huillier, Dr. Th. Herrmann, Dr. W. Bock, Dr. M. Wahl, Mr. S. Passlack, Mr. S. Schmitt, Mr. J. Mersch (Kaiserslautern). 
a)
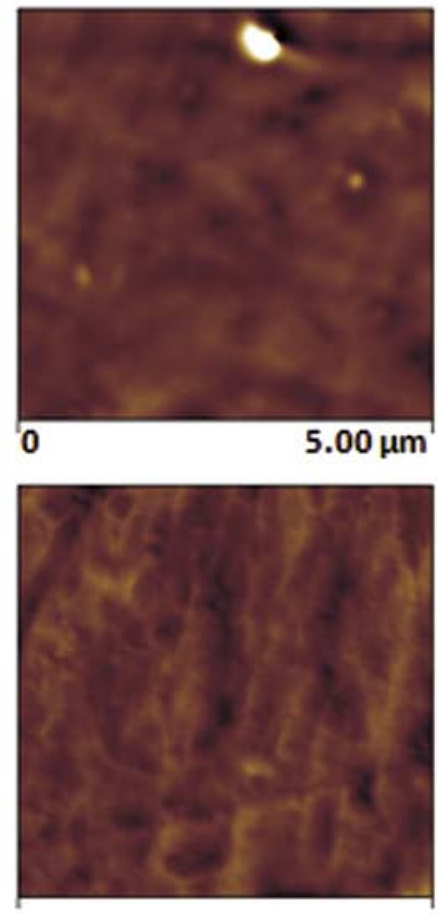

b) 0

$5.00 \mu \mathrm{m}$

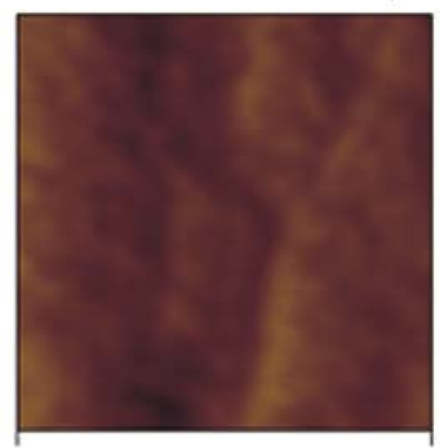

c) 0

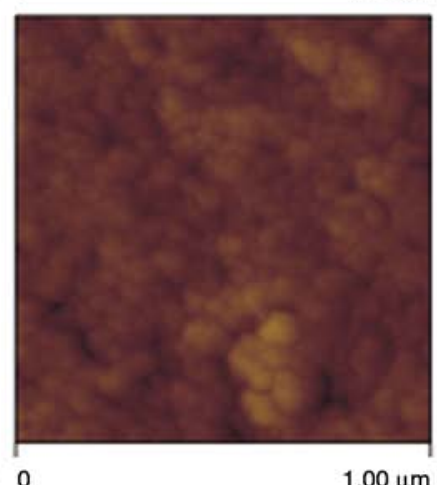

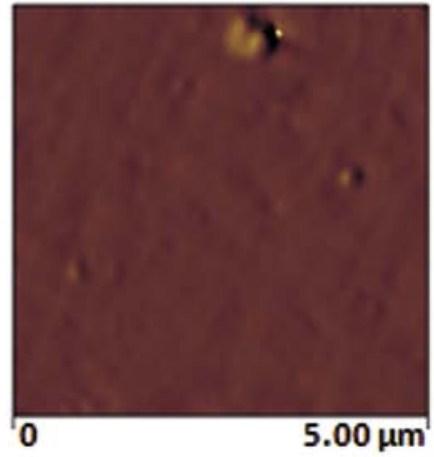

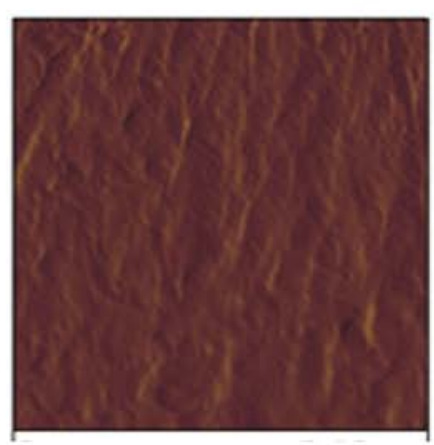

$5.00 \mu \mathrm{m}$
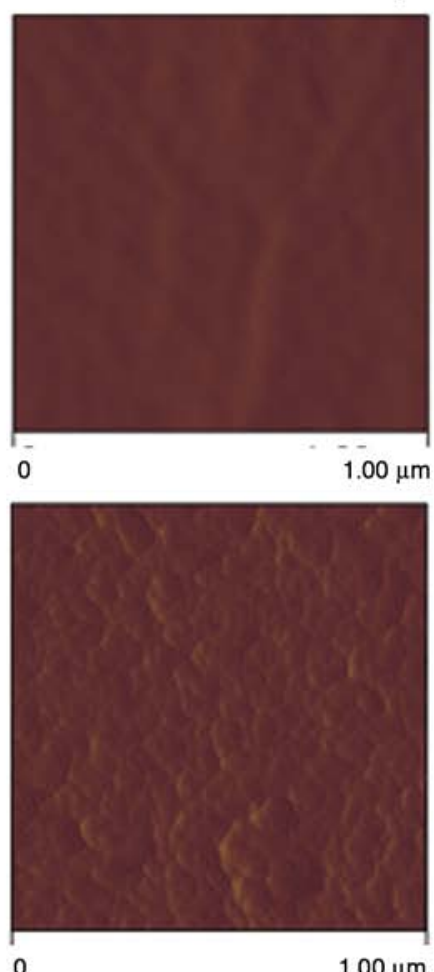
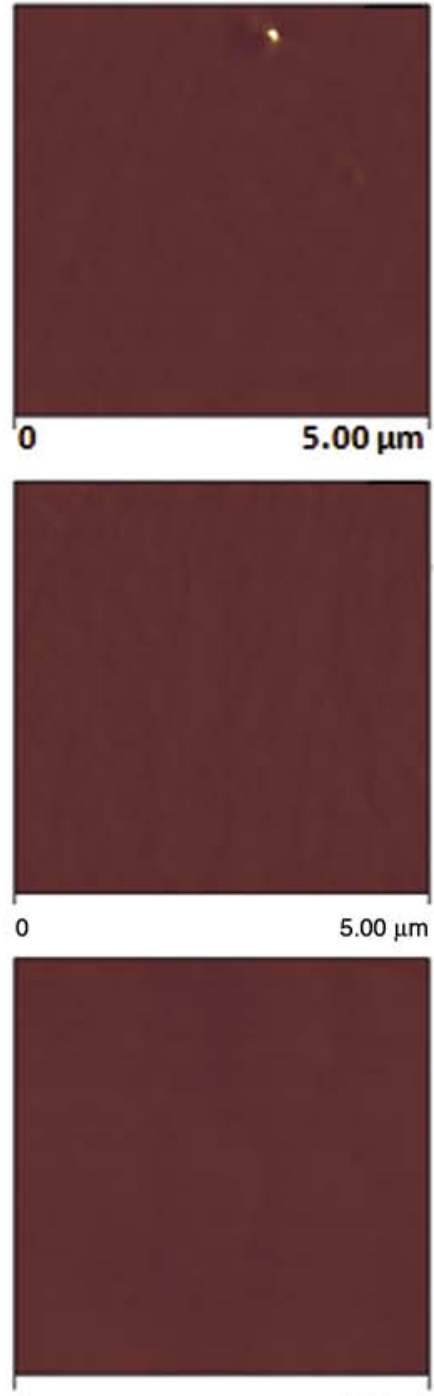

$1.00 \mu \mathrm{m}$

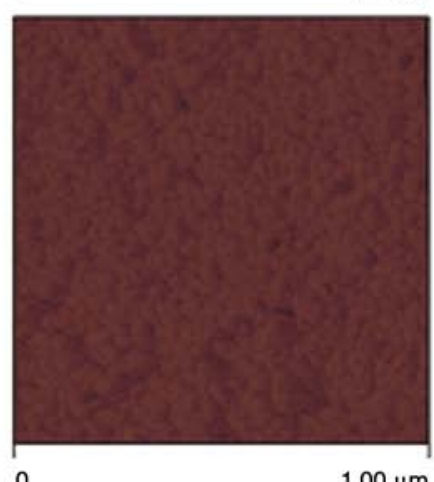

Figure 6. Height (left), amplitude (middle) and phase contrast images (right) taken by AFM-a after bombarding with various $\mathrm{Ar}^{+}$fluxes. Designations: fluxes $=0.95 \cdot 10^{18} \mathrm{Ar}^{+} / \mathrm{cm}^{2}$ (a), $1.9 \cdot 10^{18} \mathrm{Ar}^{+} / \mathrm{cm}^{2}$ (b, c) and $3.8 \cdot 10^{18} \mathrm{Ar}^{+} / \mathrm{cm}^{2}(\mathrm{~d})$

\section{References}

[1] Duchet J., Pascault J. P.: Do epoxy-amine networks become inhomogeneous at the nanometric scale? Journal of Polymer Science Part B: Polymer Physics, 41, 2422-2432 (2003).

DOI: $10.1002 /$ polb.10585
[2] Gryshchuk O., Karger-Kocsis J.: Influence of the type of epoxy hardener on the structure and properties of interpenetrated vinyl ester/epoxy resins. Journal of Polymer Science Part: A: Polymer Chemistry, 42, 5471-5481 (2004).

DOI: $10.1002 /$ pola.20371 
[3] Mosiewicki M. A., Schroeder W. F., Leite F. L., Hermann P. S. P., Curvelo A. A. S., Aranguren M. I., Borrajo J.: AFM fracture surface study of vinylester and unsaturated polyester based thermosets. Journal of Materials Science, 41, 6154-6158 (2006).

DOI: $10.1007 / \mathrm{s} 10853-006-0163-Z$

[4] Rodriguez E., Larrañaga M., Mondragón I., Vázquez A.: Relationship between the network morphology and properties of commercial vinyl ester resins. Journal of Applied Polymer Science, 100, 3895-3903 (2006). DOI: 10.1002/app.22732

[5] Li P., Yang X., Yu Y., Yu D.: Cure kinetics, microheterogeneity, and mechanical properties of the hightemperature cure of vinyl ester resins. Journal of Applied Polymer Science, 92, 1124-1133 (2004). DOI: 10.1002/app.13686

[6] Mortaigne B., Feltz B., Laurens P.: Study of unsaturated polyester and vinylester morphologies using excimer laser surface treatment. Journal of Applied Polymer Science, 66, 1703-1714 (1997).

DOI: $10.1002 /($ SICI)1097-4628(19971128)66:9<1703 $\because \mathrm{AID}-\mathrm{APP} 8>3.0 . \mathrm{CO} ; 2-\mathrm{H}$
[7] Karger-Kocsis J., Gryshchuk O., Schmitt S.: Vinylester/ epoxy-based thermosets of interpenetrating network structure: An atomic force microscopic study. Journal of Materials Science, 38, 413-420 (2003).

DOI: 10.1023/A:1021855228253

[8] Grishchuk S., Karger-Kocsis J.: Hybrid thermosets from vinyl ester resin and acrylated epoxidized soybean oil (AESO). Express Polymer Letters, 5, 2-11 (2011).

DOI: $10.3144 /$ expresspolymlett.2011.2

[9] Avilés F., Cauich-Rodríguez J. V., RodríguezGonzález J. A., May-Pat A.: Oxidation and silanization of MWCNTs for MWCNT/vinyl ester composites. Express Polymer Letters, 5, 766-776 (2011). DOI: 10.3144/expresspolymlett.2011.75 